\title{
Evolution of the TRICARE Pharmacy Benefit: A Decade of Change
}

\author{
Amy M. Lugo, PharmD, BCPS, FAPhA; Angela A. Allerman, PharmD, BCPS;
} and Shana K. Trice, PharmD

\begin{abstract}
SUMMARY
TRICARE is the military's health plan that provides coverage to 9.4 million active duty and retired uniformed services personnel and their family members. The TRICARE pharmacy benefit has undergone many changes in the last decade. These changes include assigning newly approved drugs to nonformulary status after regulatory approval, the addition of weight loss medications to the benefit, channel management point-of-service requirements for some medications, and copay increases. Several initiatives have resulted in significant cost avoidance to the Department of Defense (DoD). The purpose of this article is to discuss the changes to the TRICARE pharmacy benefit, describe the continual challenges, and estimate cost savings associated with implementation of these changes.

DoD implemented its 3-tier Uniform Formulary in 2005. Since then, many changes have been enacted, including more extensive use of prior authorization, step therapy, and quantity limits; coverage of over-thecounter medications; the retail refund program; coverage of vaccines and smoking cessation agents; mandatory mail/military treatment facility requirements; rapid review and initial nonformulary status for newly approved innovator drugs; revisions to the compounded drug benefit; initial deployment of a new medical record system; coverage of weight loss medications; and the ability to exclude medications from the Uniform Formulary.

Although the TRICARE pharmacy benefit has evolved significantly, the focus remains on the beneficiaries, with an overall goal of providing integrated, affordable, and high quality health services for the Military Health System. Challenges for the future include maximizing clinical effectiveness in the face of rising pharmaceutical costs and cost avoidance, while supporting the needs of TRICARE beneficiaries.
\end{abstract}

J Manag Care Spec Pharm. 2019;25(11):1195-1200

Copyright $\odot 2019$, Academy of Managed Care Pharmacy. All rights reserved.

$\mathrm{T}$ he TRICARE pharmacy benefit is continually evolving. Much has changed since the benefit was first described by Trice et al. in 2009. ${ }^{1}$ As of September 2018, the TRICARE health plan covered 9.4 million beneficiaries, including approximately 1.5 million active duty service members and their 2 million family members, along with 5.9 million retirees and families. The Department of Defense (DoD) has a 3-tier formulary (generic, formulary, and nonformulary). Beneficiaries may receive their medications at 3 points of service (POS): (1) at nearly 700 military treatment facilities (MTF) located worldwide, (2) at 1 mail order pharmacy, or (3) at 1 of approximately 56,000 retail network pharmacies. ${ }^{2}$ Note that the DoD pharmacy benefit is distinct from that of the Veterans Health Administration.

TRICARE has an annual $\$ 7.4$ billion pharmacy spend. In the last decade, several notable changes have occurred, including establishment of the Defense Health Agency (DHA), the addition of weight loss medications as a benefit, an expanded mail order or MTF POS requirement for nonformulary medications, as well as some chronic disease medications, and copay increases that are commensurate to commercial plans. DoD pharmacy copays are set by Congress and are generally low compared with civilian counterparts. As of February 2018, copays were $\$ 7, \$ 24$, and $\$ 53$ for a 90 -day supply at the mail order pharmacy for tier 1,2 , and 3 , respectively, and $\$ 11, \$ 28$, and $\$ 53$ for a 30-day supply at retail pharmacies. No copays are collected at MTFs for any beneficiary or at any POS for active duty service members.

The purpose of this article is to review changes to the TRICARE pharmacy benefit over the last decade, describe emerging challenges, and estimate cost savings associated with these changes. The DHA was created by Congress in October 2014 as a joint, integrated combat support agency designed to standardize the Army, Navy, and Air Force medical services. DHA supports the delivery of integrated, affordable, and highquality health services to Military Health System (MHS) beneficiaries and is responsible for driving greater integration of clinical and business processes across the MHS. ${ }^{3,4}$

On October 1, 2018, DHA assumed responsibility for the administration of MTFs, including all matters with respect to budget, information technology, health care administration and management, administrative policy and procedure, military medical construction, and any other matters that the secretary of defense determines appropriate. Additionally, a professional staff within DHA provides policy, oversight, and direction of all matters related to the administration of MTFs. ${ }^{3}$ Formulary recommendations are first determined by the DoD Pharmacy and Therapeutics (P\&T) Committee, whose mission is to uniformly, consistently, and equitably provide appropriate drug therapy to meet the clinical needs of beneficiaries in an effective, efficient, and fiscally responsible manner.

One unique aspect of DoD's formulary process is that DoD P\&T Committee recommendations are discussed in a public forum by the Beneficiary Advisory Panel (BAP), which is composed of members that represent the views and interests of a large number of TRICARE beneficiaries. Subsequently, the recommendations from the DoD P\&T Committee and the BAP are then approved by the director of the DHA. The primary responsibility of the DHA Pharmacy Operations Division (POD) is to support the DoD P\&T Committee. Other POD activities include formulary management, pharmacoeconomic analyses, utilization management, pharmacy 
- 1995 - TRICARE health care program implemented; home delivery and retail pharmacy benefit added

- 1996 - Basic core formulary (BCF) added - BCF medications must be on formulary at Military Treatment Facilities (MTFs)

- 1997 - National mail order pharmacy service begins

- 2005 - DoD Uniform Formulary Rule established with a 3-tier benefit design (tier 1, tier 2, tier 3) and the Beneficiary Advisory Panel implemented

- 2008 - Over-the-counter (OTC) pilot program begins

- 2009 - Retail refunds established

- 2010 - Vaccines covered under pharmacy benefit

- 2011 - Smoking cessation program implemented

- 2014 - Mandatory mail or MTF required for select maintenance medications; Defense Health Agency begins

- 2015 - Newly approved innovator drugs default to nonformulary; OTC benefit expanded; compound drug coverage revised

- 2016 - Medication therapy management (MTM) pilot begins

- 2017 - Initial deployment of new electronic medical record (MHS GENESIS) at 4 MTFs

- 2018 - Weight loss drug benefit added; tier 4 (completely excluded category of medications) established

Adapted from the 2018 Report to Congress. Defense Health Agency. Evaluation of the TRICARE Program: Fiscal Year 2018 Report to Congress. ${ }^{2}$ DoD=Department of Defense.

benefit design, contract administration, pharmacy informatics, database administration and analysis, MTF support, pharmaceutical refunds, and interagency collaboration.

\section{Benefit Changes and Utilization Management}

The DoD formulary decision-making process has significantly evolved, since it was first described in 2009 (Figure 1). ${ }^{1}$ The DoD P\&T Committee process starts with an in-depth clinical evaluation, which focuses on safety; efficacy; patient preference factors (e.g., tolerability, dosing frequency, and ease of use); needs of special populations; interchangeability of medications; clinical coverage (i.e., the number of agents needed to meet the majority of patient needs); and other factors (including military-specific considerations, if relevant).

The clinical evaluation is based on a thorough literature review (including pivotal trials, practice guidelines, systematic reviews and meta-analyses, and available real-world evidence), as well as DoD-specific medication usage patterns and provider feedback. The subsequent cost-effectiveness evaluation incorporates clinical considerations, DoD drug utilization, and DoD pharmacy and/or medical benefit costs and uses pharmacoeconomic and budget impact analysis models to assess the relative clinical and cost-effectiveness of individual medications and the economic impact of various formulary scenarios.

It is important to note that the TRICARE formulary covers the vast majority of prescription medications approved by the U.S. Food and Drug Administration (FDA), with rare exceptions based on benefit design (e.g., cosmetic agents) or DoD P\&T recommendation (under a recent legislative authority allowing products that offer little or no clinical advantage relative to similar agents to be excluded from coverage).

Manufacturers are offered the opportunity to provide bids based on formulary placement. Use of industry-standard programs such as prior authorization, step therapy, age edits, gender edits, and quantity limits are now fully incorporated into the decision-making process. Antidiabetic medications are an example of a class with step therapy requirements. For example, metformin is required for patients with type 2 diabetes mellitus before the use of most other antidiabetic classes unless a contraindication exists, and initial use of preferred agents is required within other antidiabetic drug classes (e.g., glucagonlike peptide-1 receptor agonists, sodium glucose co-transporter 2 inhibitors, and dipeptidyl dipeptidase- 4 inhibitors).

The DoD P\&T Committee has recently focused on market entrants where new versions of old drugs have been approved by the FDA. Examples are the numerous recent introductions of topical acne and rosacea drugs that contain the same active ingredients as older medications. Appropriately managing these types of drugs from a formulary standpoint is of increasing importance.

In 2010, TRICARE first provided access to several vaccines including H1N1, seasonal influenza, and the pneumococcal vaccine in the retail pharmacy network at a $\$ 0$ copay. The program was expanded in 2011 to include all vaccines recommended by the Centers for Disease Control and Prevention Advisory Committee on Immunization Practices "Vaccine Recommendations and Guidelines." As of October 2018, over 1.8 million vaccinations have been administered through the pharmacy benefit. Because of this program, immunizations are very accessible for TRICARE beneficiaries worldwide. While it could be assumed that improved access would increase vaccination rates across the pharmacy and medical benefit, supporting data are unavailable.

A significant change to the pharmacy benefits program occurred in October 2015. All TRICARE beneficiaries other than active duty are required to fill branded medications for chronic diseases at either the mail order or MTF pharmacies after 2 courtesy fills at a retail pharmacy. The TRICARE list of 
select maintenance drugs includes formulary and nonformulary agents (which by law are "generally available" only at the mail order POS). The list excludes medications with clinical or feasibility issues, such as drugs for acute use (e.g., antibiotics), Schedule II drugs, antipsychotics, and contraceptives. In practice, this results in a requirement to use the mail order pharmacy that is similar to many commercial plans. ${ }^{6}$

Perhaps the change to the benefit with the most effect occurred in August 2015 with the passage of the National Defense Authorization Act (NDAA) 2014. ${ }^{7}$ Before this statute, newly approved drugs defaulted to formulary or tier 2 status. Now, newly approved drugs default to nonformulary or tier 3 status, which is the commercial standard. The DoD P\&T Committee reviews newly approved drugs within 120 days after drug prices are available. As of November 2018, the DoD P\&T Committee has evaluated 194 new drugs, 48\% of which were made nonformulary. Although manufacturers are offered the opportunity to provide price concessions to DoD, the noncost benefits of this program are arguably more important than the cost benefits.

The program now ensures earlier P\&T Committee review, thereby reducing widespread adoption of a new drug and the number of patients who would have subsequently encountered a change to a higher copay before adoption of the NDAA. Ultimately, this leads to a less disruptive patient and provider experience. Expeditious review also provides an opportunity to enable utilization management tools (e.g., prior authorization and quantity limits) as needed to ensure appropriate medication use. Cost avoidance from this program was $\$ 2.1$ million as of September 2018. ${ }^{8}$

Since the 2012 tragedy of contaminated steroid injections from the New England Compounding Center, coupled with the dramatic increase in ingredient costs, much attention has focused on compounded medications. ${ }^{9,10}$ Some compounds contain ingredients that lack the support by a widely recognized body of peer-reviewed clinical evidence. Like many commercial health plans, the inappropriate use of compounded medications was a challenge for DoD, with an exponential increase in costs due to compounded prescriptions experienced from 2013 to 2015. In April 2015, compound drugs comprised only $0.5 \%$ of all TRICARE prescription volume, yet they accounted for $20 \%$ of all costs. To ensure safe and costeffective use of compounded medications for its beneficiaries, TRICARE implemented a clinical screen of every ingredient in compound drug prescriptions, effective May 1, 2015. This initiative has greatly reduced the inappropriate use of compounds and associated costs, and as of October 2018, compounded prescriptions account for about $0.17 \%$ of prescription volume and $0.14 \%$ of total costs. ${ }^{11}$

Over the past decade, the TRICARE pharmacy benefit has expanded to include smoking cessation products (March 2013), weight loss medications (May 2018), and selected over-the- counter (OTC) medications (2008 pilot program, August 2015 full benefit).

The P\&T Committee considers clinical and cost-effectiveness when selecting OTC products for coverage under the pharmacy benefit. Currently, omeprazole, loratadine, cetirizine, fexofenadine, levonorgestrel, and doxylamine are included on the formulary. All of these products require a prescription and are available at a tier 1 copay at the mail order and retail pharmacy network, with the exception of the emergency contraceptive, for which prescription and copay requirements are waived. ${ }^{6}$

The smoking cessation program was implemented in 2013 and covers varenicline, bupropion, and OTC and legend nicotine products. These agents are available at MTFs and through mail order pharmacy at no cost to the beneficiary. Coverage is limited to 2 quit attempts per a 120-day period, and quantity limits apply to the nicotine products..$^{12}$ Approximately 200,000 beneficiaries have used this benefit to date, at a cost of $\$ 25.5$ million.

In 2017, Congress authorized coverage for the medically necessary treatment of obesity, even if it is the sole or major condition treated. ${ }^{13}$ Previously, agents used for weight loss were not a covered benefit. In November 2017, the DoD P\&T Committee reviewed the weight loss products and made recommendations for tier status and prior authorization criteria, with an effective date of May 2018..$^{14}$ As of December 2018, over 6,000 patients have filled a prescription for a weight loss drug, but the long-term costs remain to be determined. In terms of cost implications of these 3 new pharmacy benefits, managing the weight loss benefit will likely be the most challenging, particularly given the rising incidence of obesity and its associated medical costs. ${ }^{15}$

\section{Cost Control Efforts}

Similar to civilian health plans, DoD uses several mechanisms to ensure appropriate use of medications, incentivize use of best value medications, and control costs. Examples include formulary management tools such as prior authorization, step therapy, quantity limits, negotiated prices with industry, generic drug contracts, channel management, and mandatory generic requirements.

One component of negotiated prices with industry includes refunds for prescriptions filled at retail network pharmacies. Legislation in the fiscal year 2008 NDAA authorized DoD to bill pharmaceutical manufacturers for refunds caused by TRICARE's overpayment on each manufacturer's covered drugs under 38 U.S.C. 8126. Beginning May 2009, DoD started collecting discounts for drugs dispensed through TRICARE retail network pharmacies. This authority represents significant savings to the DoD. As of November 2018, total collections were approximately $\$ 10.5$ billion. ${ }^{16}$

Substantial additional cost avoidance (over and above the standard retail refund) is realized as a result of the ongoing 


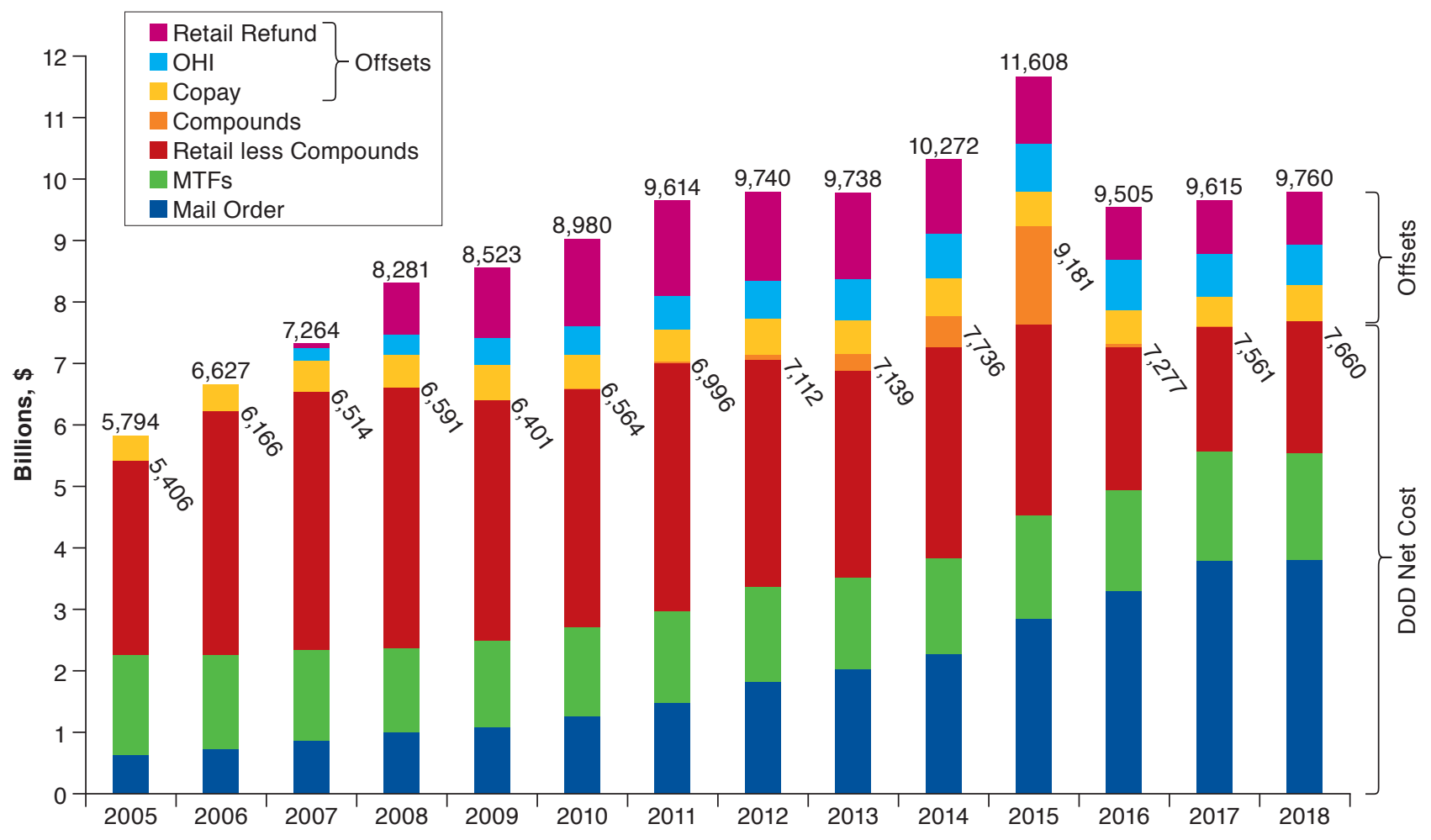

Data sources: Pharmacy Data Transaction Service (PDTS) Data Warehouse; DHA (Defense Health Agency) Pharmacy Operations Division (POD; refunds). Notes: (1) Net cost to DoD represents total prescription expenditures minus copays, OHI, and retail refunds invoiced.

(2) Mail Order dispensing fees are included; however, other retail/mail contract costs and MTF cost of dispensing are not included.

(3) Retail Refunds are reported on an accrual rather than a cash basis, based on original prescription claim data and updated refund adjustments.

(4) Retail Compound spend is not adjusted for any recoveries or settlements with compound pharmacies outside of claims reversals.

Slanted totals represent total annual costs.

DoD = Department of Defense; $M T F=$ military treatment facilities; $\mathrm{OHI}=$ other health insurance

clinical and cost-effectiveness evaluations of drugs and drug classes for the TRICARE Uniform Formulary. The DoD P\&T Committee has a robust process for negotiating additional voluntary discounts over and above the mandatory retail refunds and Federal Supply Schedule (FSS) prices. Manufacturers have been allowed to voluntarily submit bids for preferred formulary status for almost a decade. An additional \$1.9 billion in cost avoidance has been realized from the DoD P\&T Committee review process via these voluntary discounts.

Mandatory refunds combined with voluntary rebates total over $\$ 12.3$ billion in cost avoidance since inception. Other avenues for cost savings include partnering with the Veterans Health Administration for joint national contracts for selected generic products, contract compliance, mandatory generic requirements, and utilization of channel management with the requirement for select maintenance medications at mail order. These initiatives have contributed to an additional \$814 million in cumulative cost savings. Figure 2 provides a summary of the MHS outpatient drug costs over the past 13 years.

\section{Ongoing Challenges and Future Considerations}

DoD's ongoing challenges for maintaining a high value benefit include management of specialty agents, potential implementation of medication therapy management services, controlling increasing costs of generic medications, and the introduction of high-cost branded versions of old drugs. In addition, a major ongoing project is the implementation of the MHS GENESIS program.

With MHS GENESIS, TRICARE is actively implementing a new CERNER-based electronic health record (EHR), which is rolling out to all MTFs over the next decade, beginning in the Pacific Northwest. From a pharmacy viewpoint, this will have a profound effect because it aligns MTFs with the same adjudication platform as the rest of the benefit in the mail order and retail network POS. MHS GENESIS connects medical 
and dental information, enables the application of standardized workflows, integrates health care delivery, and sets data exchange standards. This is a massive undertaking, since it replaces legacy systems that have been in place for decades at nearly 700 MTFs worldwide.

The pharmacy section of the 2018 NDAA was effective on December 11, 2018, and will significantly change the TRICARE pharmacy benefit. ${ }^{17}$ The law encourages the use of pharmaceutical agents that provide the best clinical effectiveness by excluding coverage for particular pharmaceutical agents that provide very little or no clinical effectiveness relative to similar agents and gives preferential status to agents that provide enhanced clinical effectiveness. ${ }^{17}$ These completely excluded drugs will be referred to as tier 4 .

Through the years, the TRICARE pharmacy benefit has evolved significantly but remains focused on its beneficiaries. The MHS Quadruple Aim is to increase readiness, provide better care and better health, and lower cost. ${ }^{16}$ It is important to reflect on lessons learned to reach the goal of integrated, affordable, and high-quality health services for the MHS. Consistent attention should be paid to utilization management tools such as prior authorization, step therapy, and quantity limits, since they have a substantial effect on controlling costs. Additionally, leveraging innovative opportunities for market competition requires constant monitoring of products in the pipeline, novel drug mechanisms, new indications, and emerging clinical evidence. Finally, the practice of conducting clinical and cost-effectiveness evaluations collaboratively and in parallel provides the opportunity to identify the best value medications for our beneficiaries on the basis of clinical and humanistic outcomes, as well as economic considerations.

\section{Authors}

AMY M. LUGO, PharmD, BCPS, FAPhA; ANGELA A. ALLERMAN, PharmD, BCPS; and SHANA K. TRICE, PharmD, Defense Health Agency, San Antonio, Texas.

AUTHOR CORRESPONDENCE: Amy M. Lugo, PharmD, BCPS, FAPhA, Defense Health Agency, 7800 IH-10 West, Ste. 335, San Antonio, TX 78230.Tel.: 210.536.6116; E-mail: amy.m.lugo2.civ@mail.mil.

\section{DISCLOSURES}

No outside funding supported this study. The authors declare no conflicts of interest, real or apparent, and no financial interests in any company, product, or service mentioned in this program, including grants, employment, gifts, stock holdings, and honoraria. The information discussed here represents the views of the authors and does not necessarily reflect the views of the Defense Health Agency (DHA), the Department of Defense (DoD), or the Departments of the Army, Navy, and Air Force. The authors have nothing to disclose that presents a potential conflict of interest.

\section{ACKNOWLEDGMENTS}

The authors would like to acknowledge additional DHA Pharmacy Operations Division personnel in the preparation of this manuscript.

\section{REFERENCES}

1. Trice S, Devine J, Mistry H, Moore E, Linton A. Formulary management in the Department of Defense. J Manag Care Pharm. 2009;15(2):133-46. Available at: https://www.jmcp.org/doi/10.18553/jmcp.2009.15.2.133.

2. Defense Health Agency. Evaluation of the TRICARE Program: Fiscal Year 2018 Report to Congress. Access, cost, and quality data through fiscal year 2017. February 28, 2018. Available at: https://health.mil/Reference-Center/ Reports/2018/05/09/Evaluation-of-the-TRICARE-Program-Fiscal-Year-2018Report-to-Congress. Accessed September 19, 2019.

3. Military Health System. Defense Health Agency. Available at: https:// health.mil/About-MHS/OASDHA/Defense-Health-Agency. Accessed September 19, 2019.

4. Military Health System. TRICARE Health Program. Available at: https:// health.mil/Military-Health-Topics/Access-Cost-Quality-and-Safety/Accessto-Healthcare/TRICARE-Health-Plan. Accessed September 19, 2019.

5. U.S. Department of Defense, Office of the Secretary. Pharmacy Benefits Program. 32 CFR \$199.2. Available at: https://www.gpo.gov/fdsys/pkg/CFR2011-title32-vol2/pdf/CFR-2011-title32-vol2-sec199-21.pdf. Effective July 2011. Accessed December 4, 2018.

6. U.S. Department of Defense, Office of the Secretary. TRICARE Pharmacy Benefits Program. 32 CFR Ch. 1 \$199.2. Effective July 2015. Available at: https://www.govinfo.gov/content/pkg/CFR-2018-title32-vol2/pdf/CFR-2018title32-vol2.pdf. Accessed October 1, 2019.

7. U.S. Department of Defense, Office of the Secretary. TRICARE Pharmacy Benefits Program. 32 CFR Ch. 1 \$199.21. July 1, 2014. Available at: https:// www.gpo.gov/fdsys/pkg/CFR-2014-title32-vol2/pdf/CFR-2014-title32-vol2sec199-21.pdf. Accessed September 19, 2019.

8. Military Health System. Department of Defense Pharmacy and Therapeutics Committee minutes and recommedations. Second annual review of newly approved drugs. Page 19. February 2018. Available at: https://health.mil/About-MHS/OASDHA/Defense-Health-Agency/ Operations/Pharmacy-Division/DoD-Pharmacy-and-TherapeuticsCommittee/Meeting-Minutes. Accessed September 19, 2019.

9. Martin TW, Rockoff JD. Meningitis tied to pharmacy. The Wall Street Journal. October 3, 2012. Available at: https://www.wsj.com/articles/SB100008 72396390444223104578034720599010186. Accessed September 19, 2019.

10. Pollack A. Pharmacies turn drugs into profits, pitting insurers vs. compounders. The New York Times. August 14, 2014. Available at: http://nyti. ms/loyHsp7. Accessed September 19, 2019.

11. Military Health System. TRICARE Formulary. Compound drugs. Available at: https://health.mil/Military-Health-Topics/Access-Cost-Qualityand-Safety/Access-to-Healthcare/Pharmacy-Program/TRICARE-Formulary/ Compound-Drugs. Accessed September 19, 2019.

12. U.S. Department of Defense, Office of the Secretary. Pharmacy benefits program. 32 CFR Ch. 1 \$199.21. July 1, 2013. Available at: https://www.gpo. gov/fdsys/pkg/CFR-2013-title32-vol2/pdf/CFR-2013-title32-vol2-sec199-21. pdf. Accessed December 4, 2018.

13. U.S. Department of Defense, Office of the Secretary. TRICARE Pharmacy Benefits Program. 32 CFR Ch. 1 \$199.21. July 1, 2017. Available at: https:// www.gpo.gov/fdsys/pkg/CFR-2017-title32-vol2/pdf/CFR-2017-title32-vol2sec199-21.pdf. Accessed September 19, 2019.

14. Military Health System. Department of Defense Pharmacy and Therapeutics Commitee minutes and recommedations. UF drug class reviews: weight loss agents. Pages 1-5. November 2017. Available at: https:// health.mil/About-MHS/OASDHA/Defense-Health-Agency/Operations/ Pharmacy-Division/DoD-Pharmacy-and-Therapeutics-Committee/MeetingMinutes. Accessed September 19, 2019. 
15. Hales CM, Carroll MD, Fryar CD, Ogden CL. Prevalence of obesity among adults and youth: United States, 2015-2016. NCHS Data Brief. 2017;(288):1-8. Available at: https://www.cdc.gov/nchs/data/databriefs/ db288.pdf. Accessed September 19, 2019.

16. Defense Health Agency. Evaluation of the TRICARE Program: Fiscal Year 2019 Report to Congress. Access, cost, and quality data through fiscal year 2018. February 28, 2019. Available at: https://health.mil/Reference-Center/ Reports/2019/07/09/Evaluation-of-the-TRICARE-Program-Fiscal-Year-2018Report-to-Congress. Accessed September 19, 2019.
17. U.S. Department of Defense, Office of the Secretary. Pharmacy Benefits Program Reforms. Interim final rule. 83 Fed Reg 63574.

December 11, 2018. Available at: https://www.federalregister.gov/documents/2018/12/11/2018-26562/tricare-pharmacy-benefits-program-reforms. Accessed September 19, 2019. 